\title{
Percutaneous Tibial Nerve Stimulation in Chronic Post-Surgical Anorectal Pain: A Case Report
}

\author{
Marta Pacheco ${ }^{\mathrm{a}}$ João Xavier ${ }^{\mathrm{b}}$ Olga Santos $^{\mathrm{a}}$ Carina Raposo $^{\mathrm{c}}$ \\ Ana Margarida Regalado ${ }^{a, c}$ \\ a Serviço de Anestesiologia, Centro Hospitalar Universitário do Porto, Porto, Portugal; b Serviço de Anestesiologia, \\ Centro Hospitalar Universitário de São João, Porto, Portugal; ' Unidade Funcional de Dor Crónica, Centro Hospitalar \\ Universitário do Porto, Porto, Portugal
}

\section{Keywords}

Anorectal chronic pain · Post-surgical pain .

Neuromodulation

\section{Abstract}

Introduction: Anorectal pain is a symptom with a negative impact on quality of life and it can sometimes develop into a chronic pain syndrome. Structural anorectal pain is treated according to the underlying pathology. In situations of chronic post-surgical pain that is refractory to conventional therapeutic approaches, percutaneous tibial nerve stimulation (PTNS) is an option. PTNS is a neurostimulation technique used in the treatment of lower urinary tract dysfunction. There has been increasing evidence of its benefits for improving other conditions, such as chronic pelvic pain (CPP) and faecal incontinence (FI). Case Presentation: We report a case of a 45-year-old woman with chronic post-surgical anorectal pain (CPAP) treated with PTNS. The patient reported a consistent and dramatic decrease in both the frequency and intensity of pain, assessed by the Brief Pain Inventory (BPI). A decrease in the pain interference with mood, normal work, and walking/mobility was also noted, as evaluated by BPI and EQ-5D-3L questionnaires. Discussion: Neu- romodulation treatments have been reported as effective for anorectal pain, but reports on the use of PTNS are rare. The tibial nerve is easily accessible and provides an optimal site for neurostimulation without the need of an operating room or anaesthesia. The overall improvement observed in this case of chronic anorectal pain suggests a potential new area of research for PTNS.

(C) 2021 Sociedade Portuguesa de Gastrenterologia Published by S. Karger AG, Basel

\section{Estimulação Percutânea do Nervo Tibial na Dor Anal Crónica Pós-Cirúrgica - Caso Clínico}

\section{Palavras Chave \\ Dor crónica anorectal · Dor pós-cirúrgica · \\ Neuromodulação}

\section{Resumo}

Introdução: A dor anorectal é um sintoma com um impacto negativo na qualidade de vida, podendo, por vezes, desenvolver-se numa síndrome de dor crónica. A dor ano- karger@karger.com www.karger.com/pjg

Karger $\stackrel{\text { ' }}{5}$

BOPEN ACCESS (c) 2021 Sociedade Portuguesa de Gastrenterologia. Published by S. Karger AG, Basel

This is an Open Access article licensed under the Creative Common Attribution-NonCommercial-4.0 International License (CC BY-NC) (http://www.karger.com/Services/OpenAccessLicense), applicable to the online version of the article only. Usage and distribution for commercial purposes requires written permission.
Correspondence to:

Marta Pacheco, martapacheco29@gmail.com 
rectal de etiologia estrutural trata-se de acordo com a patologia subjacente. No entanto, em situações de dor crónica pós-cirúrgica refratária a abordagens terapêuticas convencionais, a estimulação percutânea do nervo tibial (percutaneous tibial nerve stimulation - PTNS) é uma opção de tratamento. A PTNS é uma técnica de neuroestimulação, estando descritos benefícios da sua aplicação no tratamento da urgência, frequência, incontinência e retenção urinária. Evidência crescente mostra, ainda, resultados promissores noutras condições, como a dor crónica pélvica e a incontinência fecal. Caso Clínico: Descrevemos um caso de uma mulher de 45 anos, com dor crónica anorectal pós-cirúrgica tratada com PTNS. Ao longo do período de seguimento, a doente reportou uma diminuição consistente e significativa na frequência e na intensidade da dor, tal como avaliado pelo Brief Pain Inventory (BPI). Adicionalmente, foi notória uma melhoria significativa de parâmetros relacionados com a qualidade de vida, avaliados pelos questionários BPI e EQ-5D-3L. Discussão: A evidência atual mostra que técnicas baseadas em neuromodulação têm sido eficazes no tratamento da dor anorectal, apesar dos estudos com PTNS ainda serem escassos. O nervo tibial é uma estrutura facilmente acessível e constitui um local óptimo para aplicação de neuroestimulação. A PTNS é uma opção terapêutica pouco invasiva, que não necessita de idas ao bloco operatório, nem de apoio de anestesia. O benefício observado do uso da PTNS neste caso sugere uma nova área de estudo e de potencial aplicabilidade para a técnica.

(c) 2021 Sociedade Portuguesa de Gastrenterologia Publicado por S. Karger AG, Basel

\section{Introduction}

Anorectal pain is a symptom with a negative impact on quality of life and can sometimes develop into a chronic pain syndrome [1]. The aetiology can generally be divided into 2 types: (a) structural disorders such as anal fissures, fistulae, haemorrhoids, and disorders often associated with infection, thrombosis, or necrosis which can subsequently lead to pain; and (b) functional anorectal disorders, such as levator ani syndrome, proctalgia fugax, and unspecified anorectal pain $[2,3]$. Structural disorders are treated according to their underlying pathology and surgery is an option in many cases. Functional disorders are treated initially with conservative measures such as lifestyle changes, diet, laxatives, and pelvic floor musculature physiotherapy. When these measures fail, both functional and structural disorders can be challenging to treat [4].
While anorectal surgery is generally well tolerated, short- and long-term complications frequently occur. Acute complications include bleeding, infection, and urinary retention. Long-term complications include faecal incontinence (FI), anal stenosis, and chronic pelvic pain (CPP) [5]. In chronic post-surgical anorectal pain (CPAP) that is refractory to conventional therapeutic approaches, percutaneous tibial nerve stimulation (PTNS) can be an option [6].

Previous literature shows that neuromodulation can be an alternative in cases of chronic anal fissure (CAF). Studies show that sacral nerve stimulation (SNS) is an effective alternative therapeutic option for CAF in patients who choose not to pursue more invasive surgical interventions [7]. The effect of SNS on anorectal function occurs at the pelvic afferent or central level via the S2-S4 nerves which contain fibres of the pudendal nerve and afferent sensory fibres from the anal sphincter and pelvic floor [8]. Based on this, Altunrende et al. [9] investigated the effect of a less invasive treatment with transcutaneous tibial nerve stimulation (TTNS) in patients with CAF. They concluded that TTNS application to the posterior tibial nerve has the potential to be an alternative treatment option for patients who seek a non-invasive treatment modality.

PTNS is another treatment option for stimulation of the tibial nerve. It is postulated that it exerts its effect through indirect modulation of the sacral plexus via the posterior tibial nerve which contains sensory, motor, and autonomic fibres from the fourth lumbar to third sacral roots. Its mechanisms of action are yet to be fully understood, but extrapolation from SNS evidence suggests sensory and motor neuromodulatory effects [8].

SNS is an invasive technique that has been used for urinary symptoms and FI, and it has been more extensively studied than PTNS. However, it requires the surgical placement of electrodes, so interest in less invasive techniques has grown [10]. The tibial nerve is easily accessible and provides an optimal site for neurostimulation [11]. The most common complications of needle placement are minor: bleeding, pain, localised musclecramping, generalised swelling, and, occasionally, occipital headaches [12].

PTNS is a neurostimulation technique commonly used in the treatment of urinary urgency, frequency, and retention as well as urge incontinence [11]. There has been increasing evidence of its benefits in improving other conditions such as CPP $[6,11]$ and FI [13]. In this context, previous clinical trials and cases series achieved a reduction in the number of incontinence episodes and an 
Table 1. Evaluation of pain characteristics and functional interference evolution throughout treatment

\begin{tabular}{|c|c|c|c|c|}
\hline Evaluation & Before PTNS & $\begin{array}{l}\text { After } \\
6 \text { sessions }\end{array}$ & $\begin{array}{l}\text { After } \\
12 \text { sessions }\end{array}$ & $\begin{array}{l}3 \text { months } \\
\text { post-treatment }\end{array}$ \\
\hline Pain frequency & always & always & always & periods of the day \\
\hline \multicolumn{5}{|l|}{ BPI } \\
\hline \multicolumn{5}{|l|}{ Pain in the last week ${ }^{1}$} \\
\hline Worse & 7 & 3 & 3 & 4 \\
\hline Least & 4 & 2 & 2 & 2 \\
\hline Average & 6 & 3 & 2 & 2 \\
\hline Now & 7 & 3 & 2 & 3 \\
\hline Treatment relief, \% & 30 & 70 & 70 & 60 \\
\hline \multicolumn{5}{|l|}{ Functional interference } \\
\hline General activity & 6 & 2 & 0 & 0 \\
\hline Mood & 8 & 2 & 0 & 0 \\
\hline Walking ability & 3 & 0 & 0 & 0 \\
\hline Normal work & 5 & 2 & 0 & 0 \\
\hline Relations with other people & 5 & 2 & 0 & 0 \\
\hline Sleep & 5 & 2 & 0 & 0 \\
\hline Enjoyment of life & 5 & 1 & 0 & 0 \\
\hline \multicolumn{5}{|l|}{ HADS } \\
\hline Depression & 9 & 3 & 5 & 0 \\
\hline Anxiety & 10 & 6 & 5 & 2 \\
\hline \multicolumn{5}{|l|}{ EQ-5D } \\
\hline \multicolumn{5}{|l|}{ Functional interference } \\
\hline Mobility & some problems & no problem & no problem & no problem \\
\hline Self care & no problem & no problem & no problem & no problem \\
\hline Usual activities & some problems & no problem & no problem & no problem \\
\hline Pain/disconfort & moderate & moderate & moderate & moderate \\
\hline Anxiety/depression & moderate & moderate & moderate & no \\
\hline EQ-VAS & 60 & 70 & 70 & 80 \\
\hline Pain after treatment session ${ }^{1}$ & 7 & 3 & 1 & - \\
\hline PGIC & - & much improved & much improved & much improved \\
\hline
\end{tabular}

PTNS, percutaneous tibial nerve stimulation; BPI, Brief Pain Inventory; HADS, Hospital Anxiety and Depression Scale; EQ-5D, a measure of health-related quality of life developed by the EuroQol Group; EQ-VAS, EuroQol visual analogue scale; PGIC, Patient Global Impression of Change.

${ }^{1}$ On a scale of $0-10$.

increase in the deferral time for deposition. Improvements in FI severity and quality of life scales were also achieved [13].

\section{Case Report}

A 45-year-old woman, whose past medical history included 5 surgeries for complex anal fistulae, was referred to our institution's Chronic Pain Unit (CPU) by her general practitioner with a 4-year history of post-surgical anorectal pain. The surgeries were described as complex procedures, with one involving exploration of the sphincter with anatomical correction.

Pain medication history included gabapentinoids, tramadol, oxycodone, and amitriptyline, with minimal pain relief. Other causes of anorectal pain had been previously ruled out by thorough testing, namely endoanal ultrasound, video-defecography, and manometry.
At the first visit, she reported pain symptoms in the endoanal area but no complaints in the external perianal region. She described a persistent, burning, and "screw-like" pain. Pain was associated with dyschezia and FI, with leakage of solids and gas. There was marked interference of her sleep and a negative impact on her quality of life. No ameliorating factors were reported. The patient's Numeric Pain Scale (NPS) scores were 6/10 at the first visit and $6 / 10$ as the worst pain in the previous 7 days.

In May 2015, PTNS became available in the CPU and the patient was enrolled for this treatment. The treatment protocol consisted of 12 once-weekly 30 -min sessions. Treatment effectiveness was monitored at the beginning of every session and at the end of treatment (Table 1). A 34-gauge needle was placed $1 \mathrm{~cm}$ posterior and $3 \mathrm{~cm}$ proximal to the medial malleolus. The Urgent $\mathrm{PC}^{\odot}$ neuromodulation system (Cogentix Medical, Inc., Minnetonka, MN, USA) was used for stimulation (Fig. 1). The frequency was $20 \mathrm{~Hz}$ and the pulse width was $200 \mu$ s. The current was gradually increased until a motor response was observed (flexion of the toes or 
plantar flexion of the foot) to determine the appropriate stimulation amplitude (possible between 0 and $9 \mathrm{~mA}$ ) and confirm correct needle placement. After this, the 30-min timed therapy session was started (Fig. 1).

During treatment, gabapentin $100 \mathrm{mg}$ twice daily and oxycodone/naloxone $5 / 2.5 \mathrm{mg}$ and amitriptyline $5 \mathrm{mg}$ once daily was maintained. No contraindications for the procedure were identified.

The impact of PTNS on the patient's pain and daily activities was evaluated with scales that are in common use in our practice: the Brief Pain Inventory (BPI), the Hospital Anxiety and Depression Scale (HADS), the EuroQuol Group Questionnaire (EQ-5D$3 \mathrm{~L}$ ), and the Patient Global Impression of Change (PGIC). Results are shown in Table 1.

By the end of the sixth PTNS session, the patient's symptoms had substantially improved. She reported a progression from 30 to $70 \%$ pain relief with the treatment. Pain intensity was significantly reduced, as well as indices of anxiety and depression, as assessed by HADS (Table 1). With the continuation of treatment, the pain scores consistently decreased. By the end of the 12 sessions, the patient had a substantial decrease in both the frequency and intensity of pain. A decrease in the interference of pain with mood, normal work, and walking/mobility was also noted, as assessed by the BPI and EQ-5D-3L questionnaires (Table 1). Although not systematically evaluated, the patient reported an important benefit in FI, with no episodes occurring after conclusion of the 12 sessions.

Substantial and sustained improvement in parameters related to quality of life and pain intensity were maintained at treatment follow-up 3 months after the last session. The patient experienced a significant reduction in the interference of pain with mood, walking, and normal work throughout the treatment period and 3 months after treatment. She also reported a global benefit to her health and an improvement in her quality of life.

Follow-up has continued until the time of writing of this paper. No relapse of symptoms occurred and no further PTNS sessions were required. The reduction in pain intensity allowed the suspension of amitriptyline from the patient's usual pain medication, while permitting superior pain control with the same doses of gabapentin and oxicodone/naloxone.

\section{Discussion}

Although chronic anorectal pain is relatively common, few studies have focused on this problem. It is defined as recurrent or persistent pain in the anal canal, usually deep and severe, that lasts for $>3$ months. Patients generally present with a combination of symptoms that can include pain, soiling, loss of blood or pus from the anus, FI, and a palpable mass in and around the anus. The combination of symptoms suggests the presence of disease, and a clinical examination is performed to assess local anal abnormalities, including anal fistula, complicated haemorrhoids, hypertrophied anal papillae, anal fissure, and perianal suppurative conditions [14].

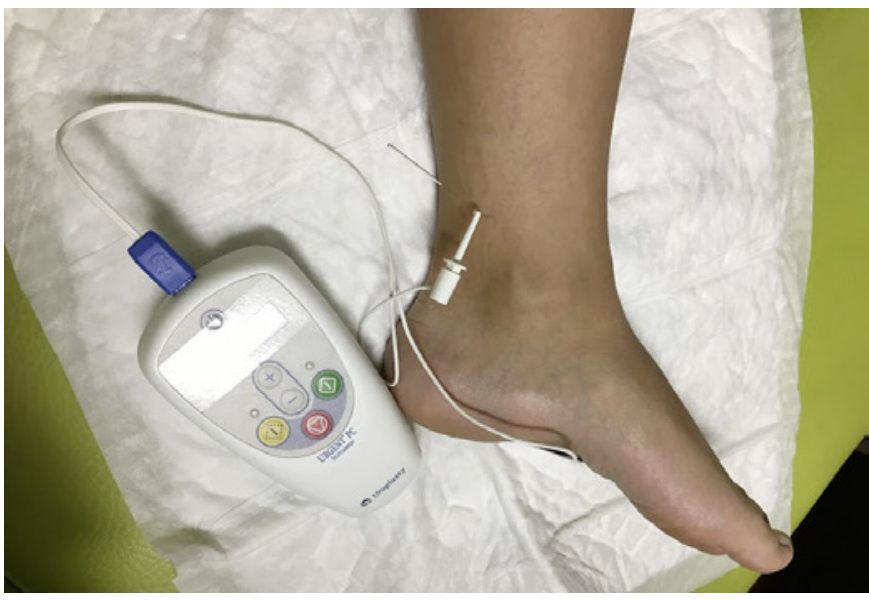

Fig. 1. Illustration of the percutaneous tibial nerve stimulation (PTNS) technique. The patient is in a sitting position with a support for her foot, and the foot is positioned in lateral rotation. The needle is placed $1 \mathrm{~cm}$ posterior and $3 \mathrm{~cm}$ proximal to the medial malleolus, attached to the Urgent $\mathrm{PC}^{\odot}$ neuromodulation system (Cogentix Medical, Inc., Minnetonka, MN, USA).

When the only presenting complaint is pain in the anal region and any previous local abnormality has been treated, with investigations unable to identify the cause of pain, the clinician is faced with a challenge. In this case, after a complete investigation to exclude other causes of pain, the diagnosis of CPAP is assumed. This is chronic pain that develops or increases in intensity after a surgical procedure and persists beyond 3 months [15].

\section{Neuromodulation}

Neuromodulation has been studied for decades, but its mechanism of action is not yet completely understood. Many theories exist. (a) In lower urinary tract dysfunction, it is thought that neuromodulation causes rebalancing of inhibitory and excitatory impulses in the central nervous system, that are responsible for bladder function [16]. (b) Regarding the impact of neuromodulation on pain, gate control theory suggests that stimulation of large somatic fibres modulates thinner afferent $\mathrm{AC}$ or $\mathrm{C}$ fibres, decreasing pain perception [17]. (c) Transcutaneous electrical and acupuncture therapy nerve stimulation lead to elevation of the endorphin levels at the spinal level $[18,19]$.

\section{Percutaneous Tibial Nerve Stimulation}

The tibial nerve is a sensory and motor nerve that originates from spinal roots $\mathrm{L} 4-\mathrm{S} 3$, which also contribute directly to sensory and motor control of the urinary bladder and pelvic floor. The interest in the tibial nerve pertains to its ease of access via surface landmarks [11]. 
PTNS is typically performed with patients in the supine position, with the knees abducted and the soles of the feet together. A 34-gauge needle is inserted into the skin 3 fingerbreadths cephalad to the medial malleolus. A grounding pad is placed on the arch of the ipsilateral foot. The amplitude of the stimulation is increased until the first toe curls or the toes fan. This technique has the advantage of being performed without requiring an operating room or anaesthesia [11].

PTNS has been more extensively studied in the treatment of pelvic organ dysfunctions commonly associated with CPP. Recent reviews show promising results both in lower urinary tract dysfunction [11], FI [13], and as a treatment option for CAF [8]. However, larger-scale studies are needed and there is no published evidence of PTNS efficacy on chronic anorectal pain.

There are no recommendations available for the ideal PTNS regimen. We therefore applied the most commonly described regimen, which consists of 30-min sessions repeated once a week for 12 weeks. Both motor and sensory responses have been described as good endpoints to confirm correct needle placement, but in this case a motor response was achieved in every treatment session. After initial treatment, PTNS can be performed as a longterm treatment to maintain the achieved benefits [20].

Larger-scale studies are needed to assess the clinical efficacy of this approach, as a single case is not sufficient to determine the important issue of the relative proportion of the placebo effect.

\section{Conclusion}

PTNS may be effective in refractory cases of CPAP, similarly to its effect on functional anorectal chronic pain syndromes, previously described in the literature. It is a novel, minimally invasive, neurostimulation modality with a low rate of complications that can be performed on an outpatient basis.

The overall improvement observed in this specific case of CPAP suggests a new area of research for PTNS. Further investigation is needed to establish PTNS as a possible alternative treatment modality for this condition.

\section{Statement of Ethics}

The patient gave her written informed consent to publish her case (including the publication of images).

\section{Conflict of Interest Statement}

The authors have no conflicts of interest to declare.

\section{Funding Sources}

The authors have no financial interests to disclose.

\section{Author Contributions}

M.P.: study conception and design, bibliographic research, data analysis and interpretation, and drafting of the manuscript. J.X.: data analysis and interpretation, bibliographic research, and drafting of the manuscript. O.S.: drafting of the manuscript. C.R. and A.M.R.: data analysis and interpretation. All authors reviewed the results, contributed to critical revision of the article, and approved the final version.

\section{References}

1 Ploteau S, Labat JJ, Riant T, Levesque A, Robert R, Nizard J. New concepts on functional chronic pelvic and perineal pain: pathophysiology and multidisciplinary management. Discov Med. 2015 Mar;19(104):185-92.

2 Bharucha AE, Lee TH. Anorectal and pelvic pain. Mayo Clin Proc. 2016 Oct;91(10):147186.

3 Simren M, Palsson OS, Whitehead WE. Update on Rome IV Criteria for Colorectal Disorders: Implications for Clinical Practice. Curr Gastroenterol Rep. 2017 Apr;19(4):15.

4 Ooijevaar RE, Felt-Bersma RJ, Han-Geurts IJ, van Reijn D, Vollebregt PF, Molenaar CB. Bo- tox treatment in patients with chronic functional anorectal pain: experiences of a tertiary referral proctology clinic. Tech Coloproctol. 2019 Mar;23(3):239-44.

5 Kunitake H, Poylin V. Complications Following Anorectal Surgery. Clin Colon Rectal Surg. 2016 Mar;29(1):14-21.

6 Engeler D, et al. EAU Guidelines on Chronic Pelvic Pain. European Association of Urology. 2018 Mar; ISBN 978-94-92671-07-3.

7 Yakovlev A, Karasev SA, Dolgich OY. Sacral nerve stimulation: a novel treatment of chronic anal fissure. Dis Colon Rectum. 2011 Mar;54(3):324-7.
8 Aho Fält U, Lindsten M, Strandberg S, Dahlberg M, Butt S, Nilsson E, et al. Percutaneous tibial nerve stimulation (PTNS): an alternative treatment option for chronic therapy resistant anal fissure. Tech Coloproctol. 2019 Apr;23(4):361-5.

9 Altunrende B, Sengul N, Arisoy O, Yilmaz EE. Transcutaneous electrical posterior tibial nerve stimulation for chronic anal fissure: a preliminary study. Int J Colorectal Dis. 2013 Nov;28(11):1583-9.

10 Peters KM. Alternative approaches to sacral nerve stimulation. Int Urogynecol J Pelvic Floor Dysfunct. 2010 Dec;21(12):1559-63. 
11 Moreira PC, Guimarães J, Raposo C, Regalado AM, Veiga D. Percutaneous Tibial Nerve Stimulation (PTNS) in iatrogenic chronic vulvar pain. IPM Reports. 2017;1:43-50.

12 Du C, Medamana J, Grigorescu B, Lazarou G. Percutaneous tibial nerve stimulation associated with occipital headaches: a review of the adverse effects of percutaneous tibial nerve stimulation. Obstet Gynecol Int J. 2018;9(5): $352-4$.

13 Arroyo Fernández R, Avendaño Coy J, Ando Lafuente S, Martín Correa MT, Ferri Morales A. Posterior tibial nerve stimulation in the treatment of fecal incontinence: a systematic review. Rev Esp Enferm Dig. 2018 Sep;110(9): $577-88$.
14 Dwarkasing RS, Schouten WR, Geeraedts TE, Mitalas LE, Hop WC, Krestin GP. Chronic anal and perianal pain resolved with MRI. AJR Am J Roentgenol. 2013 May;200(5): 1034-41.

15 Schug SA, Lavand'homme P, Barke A, Korwisi B, Rief W, Treede RD; IASP Taskforce for the Classification of Chronic Pain. The IASP classification of chronic pain for ICD-11: chronic postsurgical or posttraumatic pain. Pain. 2019 Jan;160(1):45-52.

16 Shafik A, Ahmed I, El-Sibai O, Mostafa RM. Percutaneous peripheral neuromodulation in the treatment of fecal incontinence. Eur Surg Res. 2003 Mar-Apr;35(2):103-7.
17 van Balken MR, Vergunst $\mathrm{H}$, Bemelmans $\mathrm{BL}$. Sexual functioning in patients with lower urinary tract dysfunction improves after percutaneous tibial nerve stimulation. Int J Impot Res. 2006 Sep-Oct; 18(5):470-5.

18 Oosterwijk R, Meyler W, Henley E, Scheer S, Tannenbaum J. Pain control with TENS and team nerve stimulators: A review. Crit Rev Phys Rehabil Med. 1994;6:219-58.

19 Chang CJ, Huang ST, Hsu K, Lin A, Stoller ML, Lue TF. Electroacupuncture decreases cfos expression in the spinal cord induced by noxious stimulation of the rat bladder. J Urol. 1998 Dec;160(6 Pt 1):2274-9.

20 Peters KM, Carrico DJ, Wooldridge LS, Miller CJ, MacDiarmid SA. Percutaneous tibial nerve stimulation for the long-term treatment of overactive bladder: 3-year results of the STEP study. J Urol. 2013 Jun;189(6):2194201 